\title{
Improving Management Quality of Newly-Established Universities Laboratory by $5 S$ Concept
}

\author{
Ye BI \\ Engineering Training Center, Shanghai Polytechnic University, Shanghai 201209, China \\ biye@sspu.edu.cn
}

Keywords: 5S; newly-established universities; laboratory; management system

\begin{abstract}
In recent years, an example for the laboratory development and construction of Shanghai Polytechnic University. We introduced the 5S management concepts from the corporation. Under the new condition, we analyzed the direction of laboratory construction for newly-established universities. Applied the 5S combined with LIMS (Laboratory Information Management System) to improve the quality of laboratory construction and management. The implementation of 5S management is good for teachers and students to provide better teaching and research environment.
\end{abstract}

\section{Introduction}

Newly-established universities aim to undertake the responsibilities for training highly-skilled professionals. However, due to their relatively short history, their education quality raised many discussions. For new universities and colleges, improvements in undergraduate education quality are closely related to the establishment and management of science labs. A science lab is a key component in training highly talented, skilled, and practical professionals, as well as a good way for new universities to improve their quality of education. [1]

In recent years, many universities and colleges re-planned and adjusted their infrastructure of science labs. However, there are some common challenges in the establishment and management of science labs. In order to overcome those challenges, Shanghai Polytechnic University communicated closely with professors and students, applied the concept of the 5S management approach, and used the LIMS (Lab Information Management System) to improve the development and management of science labs, consequently providing a better education and research environment to professors and students.

\section{The Concept of 5S Management}

The concept of 5S management was first introduced in Japan. It was originally used to effectively manage work-site factors of production, such as personnel, facilities, materials, and production procedures. 5S stands for five Japanese words, whose translations all start with the letter "s”, namely, Sort (Seiri), Set in Order (Seiton), Shine (Seiso), Standardize (Seiketsu), and Sustain (Shitsuke). [2]

Seiri means classifying all objects in a science lab into two categories, namely, necessary and unnecessary, retaining necessary items, and disposing unnecessary ones. Seiton means arranging all necessary objects to their proper positions according to the lab's regulations with clear labels and recording their quantities. Seiso means keeping the lab clean, removing dirt and deterioration. Seiketsu means regulating and standardizing the best practices following the previous three "S"s, as well as implementing and maintaining the standards. Shitsuke means ensuring that each lab administrator develops good work habits and always follows the best practices. Good work habits and manners of lab administrators are fundamental for lab management. The concept of 5S aims to improve the management quality of science labs and provide excellent teaching and research environment for professors and students. 


\section{The Status of Lab Management at Newly-Established Universities}

\section{A. Lack of Overall Planning and Management}

Many newly-established universities are established based on merger or consolidation of post-secondary vocational schools. Their education and operation histories are very short, but they face the urging needs for lab establishment and development. At present, some of them still do not have an overall institutional level plan for science labs or something like that. For instance, redundancies may be found in the construction of electronic and electrical labs. Affiliated colleges may construct multiple labs with similar functionalities due to the lack of overall planning and repeated purchases of same devices, some of which are never used [3].

\section{B. Out-dated Management Approaches and Incomplete Systems}

Many new undergraduate universities are established based on merger or consolidation of post-secondary vocational schools. Therefore, some labs may belong to affiliated colleges. This indicates that their management responsibilities are assigned to teaching and research offices. And not sufficient attention is paid to the importance of the management of experimental devices, so that the usage rate of many devices is far from being optimal.

Many universities have still not established complete regulation systems for science lab management. Efforts were only made with respect to facilities without matching management method, i.e. lack of daily management and maintenance of devices.

\section{Information Level needs to be Improved}

Currently, some newly-established universities still use traditional management approaches. For instance, the usage status of devices and power supplies is monitored by the lab staff manually, the recording of the device leasing is made on paper etc. It was proved that such approaches can lead to the waste of human resources and low working efficiency. With the expansion of newly-established universities and an increase in the number of students, the use of science labs increases as well, which challenges the traditional management approaches.

With the continuing improvements in science lab management systems, it becomes an urging need for newly-established undergraduate universities to standardize operations and workflows in science labs, better satisfy students' demands for labs, help lab administrators to achieve efficient and effective management of remote labs, and consolidate lab teaching resources.

\section{Improving Lab Management Quality Using 5S Concept Combined with LIMS Management System}

\section{A. Overall Planning and Promoting 5S Concept}

In 2010, Shanghai Polytechnic University set up an experiment and training management office to implement eight major principles of construction and management of all science labs, including unified arrangement, unified planning, unified construction, unified management standardization, unified usage management, unified resource distribution, unified maintenance, and unified examination and evaluation. This can help to effectively consolidate university-wide resources and contribute to the improvement in science lab management.

Shanghai Polytechnic University has established a variety of rules and regulations related to science lab management based on the 5S concept, including 5S device management rules, 5S low-price consumables management approaches, 5S device repair and maintenance management approaches, 5S device disposal management approaches etc. Specific personnel are appointed to inspect lab assets management and annual inventory to ensure consistency between inventory and records.

The promotion and execution of the $5 \mathrm{~S}$ management concept, as well as encouraging lab instructors to follow 5S standards, have ensured the quality of experiments and safety, increased working efficiency, and improved labs' overall image. By practicing $5 \mathrm{~S}$ standards in their experiments, students improve their professional knowledge, practical abilities, comprehensive qualities, teamwork spirits, and sense of safety. Figure 1 illustrates how the university, teachers, and students work together to promote and execute the 5S management concept. 


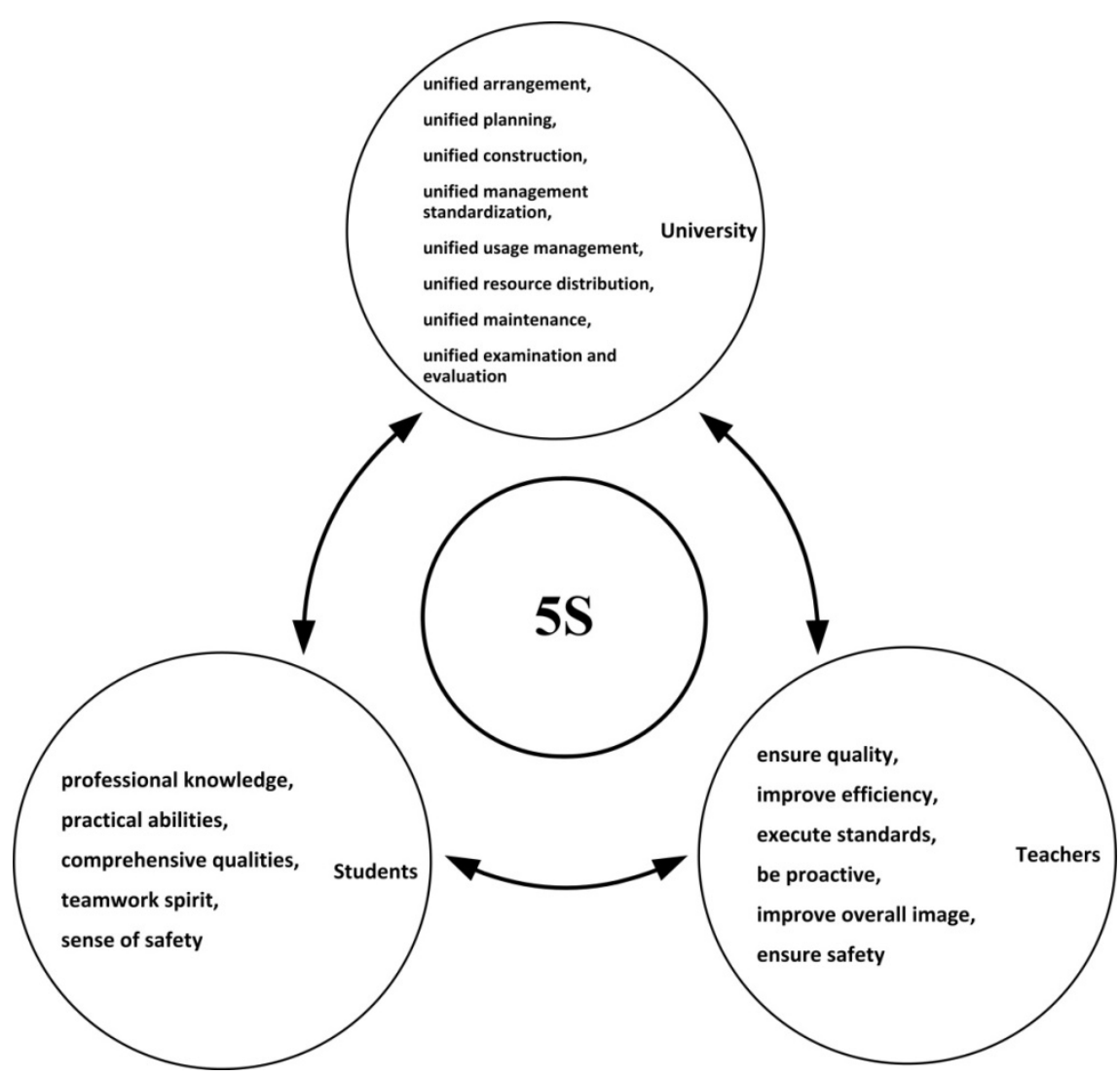

Fig. 1 Promotion and Execution of 5S Management Concept

\section{B. Integrating 5S Concept in Management System}

The university has documented 'The Rules and Regulations of 5S Management of Science Labs', which is a plan and design of a 5S-concept-centralized management system from the point of view of teachers and students based on the features and specifications of science labs. According to the $5 S$ concept, the standardized management of daily lab work is divided into management of lab documents, lab environment, lab devices, lab materials etc. Lab instructors and new teachers are regularly trained in 5S management based on the established 5S regulations. Teachers promote the 5S concept to students during lab courses to help them experience the enterprise-level standardization of 5S management in their daily study. Figure 2 illustrates how the $5 \mathrm{~S}$ concept is integrated into day-to-day lab operations. [4]

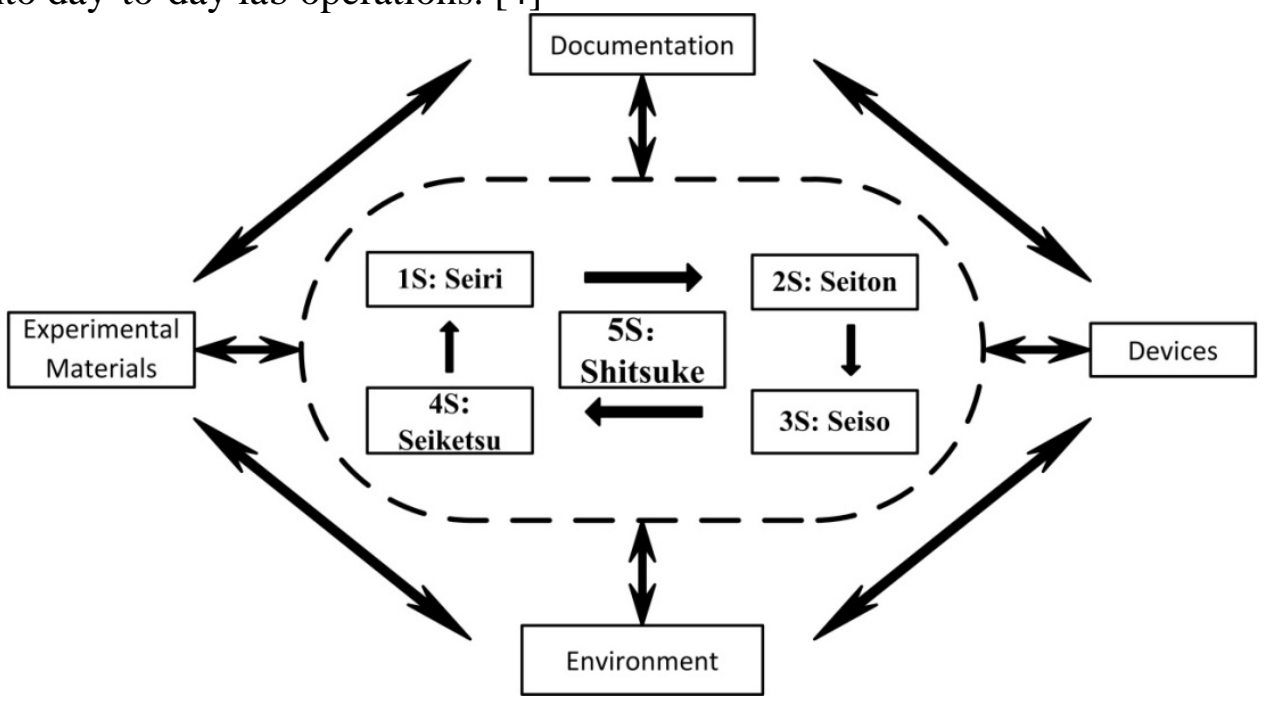

Fig. 2 Integration of 5S Concept into Day-to-Day Lab Operations 


\section{Use LIMS Lab Management System to Fully Implement 5S Concept}

To better fulfill and implement the 5S concept, the university uses the LIMS lab management system, and combines the $5 \mathrm{~S}$ concept with the lab management system. The university established a smart comprehensive lab management system, optimized functionalities of lab constructions, usage, evaluation, and so on, and developed a two-level (university level and department level) 5S management model. The university level is responsible for overall planning of all science labs of the university, while the department level is responsible for lab operation management and teaching platform management. Efforts were also made to promote regularization of smart lab management and improve the management of lab courses, experiment arrangement etc. Expansions were widely applied to access the control and power supply systems based on the current infrastructure. Hardware upgrades were also made in the previous access control system with additional electric lock control, data acquisition, and power supply. The B/S framework is currently used in the server room management system. The server room and science labs are managed in a unified way for the information management of experiments and training. Figure 3 illustrates the topology of the lab power supply system.

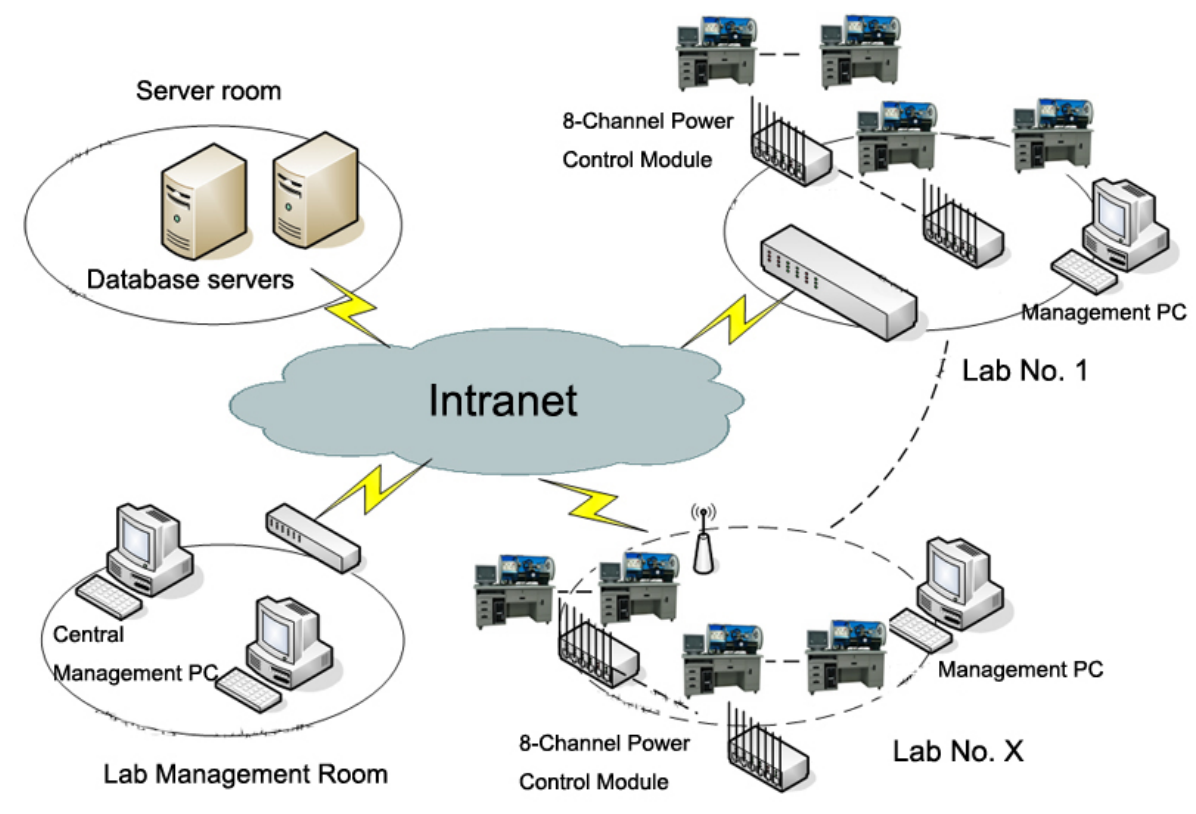

Fig. 3 Topology of Lab Power Supply System

\section{Conclusion}

The promotion and implementation of the $5 \mathrm{~S}$ management concept in science labs is a meticulous procedure. For newly-established undergraduate universities and colleges, it requires not only persistence, but also integration in the day-to-day teaching practices. 5S management is not a mere formality, but requires long term promotion and persistence. With the increased information level of the modern society, it is crucial to combine the 5S management concept and LIMS lab management system to achieve better lab management and improve efficiency, safety and reliability. Both research and practice demonstrate that the 5S management concept improves the quality of lab management and can be further studied and promoted.

\section{References}

[1] HU Shou-gen,YIN Ge-lan, Tradition, Characteristic, Innovation: The Way of Sustainable Development in Application-oriented University, Journal of Shanghai Second Polytechnic University. (2010) 
[2] GU Shu-bo, YU Zhen-wen, FAN Guang-hua, LI Xiang-dong, Improving the Management Level of Research Laboratory by Applying“5S”. (2006)

[3] ZHAO Yue-min, Laboratory is the Nucleus Competing Power of Universities. (2005)

[4] YAO Yu-chun, WANG Zhao-li, Introduce the“ $5 S$ "idea to laboratory management in universities and colleges. (2002) 